\title{
Palinomorfos de fungos e criptógamas em sedimentos quaternários de duas matas com Araucária, Planalto leste do Rio Grande do Sul, Brasil ${ }^{1}$
}

\author{
Caroline Scherer ${ }^{2,3}$ e Maria Luisa Lorscheitter ${ }^{2}$
}

Recebido em 24/01/2007. Aceito em 14/05/2007

\begin{abstract}
RESUMO - (Palinomorfos de fungos e criptógamas em sedimentos quaternários de duas matas com Araucária, Planalto leste do Rio Grande do Sul, Brasil). Pólen, esporos e demais palinomorfos preservados em sedimentos são material de referência básico em estudos paleoambientais. A presente pesquisa tem como objetivo apresentar a taxonomia de palinomorfos correspondentes a fungos e criptógamas contidos em sedimentos do interior de duas matas com Araucária do Planalto leste do Rio Grande do Sul e, assim, fornecer subsídios para reconstituições paleoambientais na região. A análise envolveu amostras de dois perfis sedimentares holocênicos de São Francisco de Paula (perfil 1, Alpes de São Francisco, 132 cm; perfil 2, Banhado Amarelo, $101 \mathrm{~cm}$ ), coletados com o Amostrador de Hiller. O processamento químico das amostras seguiu o método padrão, com $\mathrm{HCl}, \mathrm{HF}, \mathrm{KOH}$, acetólise e montagem das lâminas em gelatina-glicerinada. A análise foi realizada em microscopia óptica. São apresentados palinomorfos de oito fungos, seis algas, cinco briófitos e 19 pteridófitos. A descrição de cada material é acompanhada de ilustrações e, sempre que possível, de dados ecológicos do organismo de origem. A grande quantidade de palinomorfos distintos, bem preservados nos sedimentos, mostra a potencialidade deste material em oferecer informações ambientais relevantes, junto com grãos de pólen, no estudo da gênese e expansão da mata com Araucária.
\end{abstract}

Palavras-chave: Palinologia, Quaternário, mata com Araucária, fungos, criptógamas

ABSTRACT - (Palynomorphs of fungi and cryptogams in Quaternary sediments from two Araucaria forests, Eastern Plateau of Rio Grande do Sul, Brazil). Pollen, spores and other palynomorphs preserved in sediments are basic reference material for palaeoenvironmental studies. The aim of this research is to present the taxonomy of fungal and cryptogamic palynomorphs contained in sediments from two Araucaria forests on the Eastern Plateau of Rio Grande do Sul, thus contributing to palaeoenvironmental reconstitution in the region. The analysis involved samples from two Holocene sedimentary profiles from São Francisco de Paula (profile 1, Alpes de São Francisco, 132 $\mathrm{cm}$; profile 2, Banhado Amarelo, $101 \mathrm{~cm}$ ), collected with a Hiller Sampler. Chemical processing of the samples followed standard methodology, using $\mathrm{HCl}, \mathrm{HF}, \mathrm{KOH}$, acetolysis and slide mounts in glycerol-jelly. Light microscopy was used in the analysis. Palynomorphs of eight fungi, six algae, five bryophytes and 19 pteridophytes are presented. The description of each palynomorph is followed by illustrations and, whenever possible, by ecological data from the original organism. Distinct palynomorphs preserved in the sediments reveal the potential of this material in providing relevant environmental information, in association with pollen grains, in the study of genesis and expansion of the Araucaria forest.

Key words: Palynology, Quaternary, Araucária forest, fungi, cryptogams

\section{Introdução}

Os padrões fitogeográficos observados na atualidade são resultantes de mudanças climáticas e vegetacionais ocorridas no passado. $\mathrm{O}$ estudo da sucessão vegetal permite, portanto, o conhecimento dos processos históricos envolvidos na gênese das formações vegetais e, assim, a melhor compreensão da dinâmica e das tendências naturais da vegetação e do clima, importantes na avaliação e no monitoramento ambiental. Pólen, esporos e outros palinomorfos encontram-se em diferentes ambientes deposicionais, preservando suas características morfológicas, diretamente relacionadas à espécie de origem. A palinologia de perfis sedimentares, aliada a datações radiométricas fornece, assim, uma das principais ferramentas em reconstituições paleoambientais. Para tanto, a correta identificação dos palinomorfos contidos nos sedimentos é imprescindível, o que torna de grande valia os catálogos palinológicos de referência, tanto da flora atual quanto da pretérita.

O Planalto leste do Rio Grande do Sul oferece vários locais para estudos palinológicos de sedimentos, que podem elucidar a história dos últimos milênios da região em relação à mata com Araucária e à própria Araucaria angustifolia (Bertol.) Kuntze, espécie que

\footnotetext{
Parte da tese de doutorado da primeira Autora, Programa de Pós-Graduação em Botânica, Universidade Federal do Rio Grande do Sul

2 Universidade Federal do Rio Grande do Sul, Instituto de Biociências, Departamento de Botânica. Av. Bento Gonçalves 9500, 91540-000 Porto Alegre, RS, Brasil

3 Autor para correspondência: caroline.scherer@ufrgs.br
} 
exige um clima com, no mínimo, $1.400 \mathrm{~mm}$ de chuvas anuais, sem estações secas regulares ao longo do ano (Hueck 1953; Backes 1988; Behling et al. 2004). A dinâmica da mata com Araucária no Holoceno tem despertado a atenção de muitos pesquisadores, mas ainda são escassos os trabalhos sobre palinologia de sedimentos na região envolvendo análise de paleoambientes (Roth \& Lorscheitter 1993; Behling et al. 2001; 2004; Leonhardt \& Lorscheitter 2007).

O presente trabalho apresenta o resultado da análise palinológica qualitativa de dois perfis sedimentares quaternários do interior de mata com Araucária, localizados no Município de São Francisco de Paula, Planalto leste do Rio Grande do Sul. É feita a análise dos referidos perfis, abrangendo palinomorfos relacionados a fungos, algas, briófitos e pteridófitos, como material de referência. O trabalho aborda a taxonomia de cada material, com caracterizações morfológicas sucintas e fotomicrografias ópticas. Sempre que possível, dados ecológicos do organismo de origem acompanham as descrições. Pretende-se, assim, fornecer material de referência básico para mais estudos paleoambientais na região.

\section{Material e métodos}

Os perfis localizam-se em Alpes de São Francisco - perfil $1\left(29^{\circ} 29^{\prime} \mathrm{S}-50^{\circ} 36^{\prime} \mathrm{W}, 132 \mathrm{~cm}\right.$, base datada em $12650 \pm 70$ anos AP, Beta 200630) e Banhado Amarelo - perfil $2\left(29^{\circ} 18^{\prime} \mathrm{S}-50^{\circ} 08^{\prime} \mathrm{W}, 101 \mathrm{~cm}\right.$, base datada em $3840 \pm 40$ anos AP, Beta 233965), município de São Francisco de Paula (Fig. 1). Os perfis foram coletados no interior de mata com Araucária, usando-se o Amostrador de Hiller (Faegri \& Iversen 1989), em secções de $26 \mathrm{~cm}$, posteriormente alinhadas. Foram retiradas, em intervalos regulares, 15 amostras do perfil 1 e 8 do perfil 2, cada uma de $8 \mathrm{~cm}^{3}$. As datações por ${ }^{14} \mathrm{C}$ foram realizadas no laboratório Beta Analytic Inc., Miami, Flórida. O processamento químico das amostras para análise palinológica seguiu Faegri \& Iversen (1989), usando-se HCl, HF, KOH e acetólise, com filtragem em malha de $250 \mu \mathrm{m}$ e montagem das lâminas em gelatina-glicerinada. A análise foi feita em microscópio óptico Carl Zeiss Jena em aumento de $400 \mathrm{x}$. Os palinomorfos foram fotomicrografados em microscópio óptico Diaplan Leitz, em aumento de 1.000 x. A palinoteca de plantas atuais do Laboratório de Palinologia do Departamento de Botânica da Universidade Federal do Rio Grande do Sul e diversos catálogos palinológicos serviram de base para a identificação do material. Os palinomorfos foram

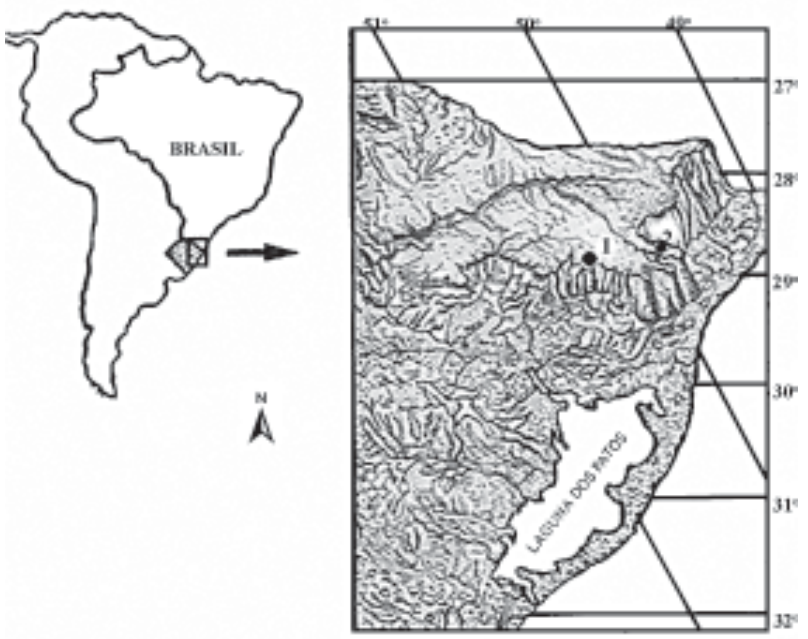

Figura 1. Estado do Rio Grande do Sul e localização dos perfis sedimentares estudados: 1. Alpes de São Francisco (292'ㄱ' $\left.50^{\circ} 36^{\prime} \mathrm{W}\right)$ e 2. Banhado Amarelo ( $\left.29^{\circ} 18^{\prime} \mathrm{S}-50^{\circ} 08^{\prime} \mathrm{W}\right)$, São Francisco de Paula, Rio Grande do Sul, Brasil.

determinados na categoria taxonômica mais inferior possível. A denominação “Tipo" foi empregada sempre que não houve possibilidade de assegurar a determinação, conforme o usual em Palinologia de sedimentos (Berglund 1986). O material foi separado por números quando não houve possibilidade de determinação, visando futura identificação (ex: Esporo 1). Os palinomorfos são apresentados em ordenação sistemática, utilizando-se Alexopoulus et al. (1996) para fungos, Round (1973) para algas, Bold et al. (1987) para briófitos e Tryon \& Tryon (1982) para pteridófitos. Para fungos e algas a nomenclatura utilizada baseou-se na referência indicada nas descrições taxonômicas, e para briófitos e pteridófitos no glossário de Punt et al. (2007). Os palinomorfos foram descritos de modo sucinto, usando-se as características distintivas básicas para a identificação. As medidas foram realizadas em ocular de fio móvel e convertidas para micrômetros. Nas medidas dos esporos de briófitos e pteridófitos foram usados, sempre que possível, os eixos polar e equatorial. As descrições do material são acompanhadas de dados ecológicos do organismo de origem, fornecendo informações para análise de paleoambientes. A maioria das fotomicrografias foi realizada em aumento de 1.000 x (filme T-MAX 100).

\section{Resultados e discussão}

A análise palinológica qualitativa resultou num total de 38 palinomorfos (oito fungos, seis algas, cinco 
briófitos e 19 pteridófitos) preservados ao longo dos dois perfis sedimentares.

\section{Fungos}

Filo Glomeromycota

Classe Glomeromycetes

Ordem Glomerales

Família Glomeraceae

\section{Glomus Tul. \& C. Tul.}

Fig. 2

Clamidósporo esferoidal, psilado, preso a filamento de hifa cenocítica, formando micélios ramificados. Diâmetro: 28-54 $\mu \mathrm{m}$. Referência: Schüßler et al. (2001). Observação: este material foi citado para o Rio Grande do Sul pelos antigos nomes Rhizophagites Rosendahl (Lorscheitter 1988) e Rhizophagus Dang (Neves \& Lorscheitter 1992; Neves \& Bauermann 2003). Dados ecológicos: mais comum entre os fungos micorrízicos arbusculares. Em solo, como endossimbionte em raízes de numerosas plantas vasculares (Schüßler et al. 2001). Segundo MoreiraSouza et al. (2003), espécies do gênero Glomus estão entre os principais fungos micorrízicos arbusculares presentes na mata com Araucária.

\section{Filo Ascomycota}

Classe Ascomycetes

Ordem Sordariales

Família Sordariaceae

\section{Gelasinospora adjuncta Cain}

Fig. 3

Ascósporo elipsoidal, psilado. Pequenas perfurações circulares, distribuídas uniformemente pela superfície. Coloração marrom-escuro. Eixo maior: cerca de $35 \mu \mathrm{m}$. Eixo menor: cerca de $25 \mu \mathrm{m}$. Referência: Hooghiemstra (1984). Dados ecológicos: espécie decompositora de excrementos, madeira carbonizada e lignina (Van Geel 1978).

\section{Tipo Helicoon pluriseptatum Beverw.}

Fig. 4

Conídio de disposição helicoidal, septado, psilado. Coloração castanho-escuro. Diâmetro: 24-26 $\mu \mathrm{m}$. Referência: Hooghiemstra (1984), Ingold \& Hudson (1993). Dados ecológicos: segundo Ingold \& Hudson (1993) o gênero Helicoon compreende espécies aeroaquáticas, que geralmente crescem sob folhas submergidas, em condições de baixa aeração. Primeira citação para o Quaternário do Rio Grande do Sul.
Filo Basidiomycota

Classe Basidiomycetes

Ordem Polyporales

Família Atheliaceae

\section{Tipo Athelia Pers.}

Fig. 5

Células esferoidais, psiladas, densamente agrupadas, formando uma estrutura esferoidal a elipsoidal. Diâmetro da estrutura: 24-63 m. Diâmetro das células: 6-10 $\mu \mathrm{m}$. Referência: Hooghiemstra (1984). Dados ecológicos: o gênero inclui possivelmente patógenos de líquens e algas (Kirk et al. 2001).

Outros esporos

\section{Esporo 1}

Fig. 6

Unidade de dispersão fusiforme, monosseptada, psilada. Robusta. Coloração marrom-escura. Eixo maior: 42-47 $\mu \mathrm{m}$. Eixo menor: 17-24 $\mu \mathrm{m}$.

\section{Esporo 2}

Fig. 7

Radiossimétrico, esferoidal, microequinado. Espinhos muito finos, densamente distribuídos por toda a superfície. Diâmetro: 11-13 $\mu \mathrm{m}$.

\section{Esporo 3}

Fig. 8

Unidade de dispersão fusiforme, estreita, monosseptada estriada. Estrias longitudinais muito próximas, finas e paralelas. Coloração marrom-escura. Eixo maior: 25-30 $\mu \mathrm{m}$. Eixo menor: 7-10 $\mu \mathrm{m}$.

\section{Esporo 4}

Fig. 9

Unidade de dispersão fusiforme, com número variável de septos, de coloração castanha-escura. Envoltório hialino, com dobras irregulares por toda a superfície. Eixo maior: 30-38 $\mu \mathrm{m}$. Eixo menor: 12-13 $\mu \mathrm{m}$.

\section{Algas}

Divisão Chlorophyta

Classe Chlorophyceae

Ordem Chlorococcales

Família Dyctyosphaeriaceae

9. Botryococcus Kützing

Fig. 10-11

Colônia irregularmente lobada, de tamanho 
variável e psilada, formada por inúmeros indivíduos unicelulares, densa e concentricamente dispostos. Escura. Eixo maior da colônia: 24-50 $\mu \mathrm{m}$. Eixo menor da colônia: 18-38 $\mu \mathrm{m}$. Referência: Hooghiemstra (1984). Dados ecológicos: em água doce, em poças ou lagos (Erdtman 1969).

Classe Zygnemaphyceae

Ordem Zygnematales

Família Zygnemataceae

\section{Debarya (De Bary) Wittrock}

Fig. 12-13

Zigósporo formado por dois hemisférios, hialino. Cada hemisfério com espessamento anelar característico em vista frontal, apresentando estrias finas, pouco perceptíveis e radialmente dispostas no centro, e outras, também de disposição radial, na periferia. Diâmetro equatorial: 38-39 $\mu \mathrm{m}$. Referência: Hooghiemstra (1984). Observação: os zigósporos encontrados apresentam-se com apenas um dos hemisférios. Dados ecológicos: em água doce, estagnada e com pouca profundidade (Van Geel \& Van Der Hammen 1977).

\section{Mougeotia C. A. Agardh}

Fig. 14

Zigósporo aproximadamente quadrangular em vista frontal, psilado, com dobras características nos ângulos. Hialino. Largura: 40-48 $\mu$ m. Referências: Van Geel (1978), Hooghiemstra (1984). Dados ecológicos: em água doce e solos úmidos (Joly 2002).

\section{Spirogyra Link}

Fig. 15

Zigósporo esferoidal a elipsoidal, hialino ou amarelado. Parede celular lisa, envolvendo toda a superfície, ou reticulada. Retículo robusto e irregular. Eixo maior: cerca de $80 \mu \mathrm{m}$. Eixo menor: 22-63 $\mu \mathrm{m}$. Referência: Hooghiemstra (1984). Dados ecológicos: como em Mougeotia.

\section{Zygnema C.A. Agardh}

Fig. 16-17

Zigósporo esferoidal a elipsoidal, psilado, hialino, apresentando características reentrâncias circulares, pequenas ou robustas, regularmente distribuídas por toda a superfície. Eixo maior: 49-50 $\mu \mathrm{m}$. Eixo menor: 44-47 $\mu \mathrm{m}$. Referências: Van Geel (1978), Hooghiemstra (1984). Dados ecológicos: em água doce e em solos úmidos (Smith 1987; Joly 2002). Segundo
Van Geel \& Van Der Hammen (1977) também ocorre em água estagnada e com pouca profundidade.

\section{Incertae sedis}

\section{Pseudoschizaea rubina Rossignol ex Christopher} Fig. 18-19

Grão estriado, circular em vista frontal, inaperturado, hialino. Estrias finas e concêntricas, formando anéis e espiras às vezes incompletos. Diâmetro em vista frontal: 33-37 $\mu \mathrm{m}$. Referência: Christopher (1976). Observação: o material é citado em trabalhos mais antigos como a forma $\mathrm{A}$ de Concentricystes rubinus Rossignol (Rossignol 1962). Dados ecológicos: material sem afinidade botânica confirmada, possivelmente originado de algas dulciaqüícolas (Rossignol 1962). Christopher (1976) incluiu a espécie em um grupo incerto dentro de algas.

\section{Briófitos}

Divisão Anthocerotophyta

Classe Anthocerotopsida

Ordem Anthocerotales

Família Anthocerotaceae

\section{Aspiromitus punctatus (L.) Schljakov} Fig. 20

Radiossimétrico, heteropolar, circular a subtriangular em vista polar. Trilete, raios com extremidade distal bifurcada. Exospório reticuladoequinado no pólo distal, psilado no proximal. Retículo grosseiro, com projeções espinescentes alongadas e freqüentemente bifurcadas a trifurcadas, algumas simples, sobre o muro. Eixo equatorial: cerca de $60 \mu \mathrm{m}$. Dados ecológicos: cosmopolita, em relvas úmidas (Schultz 1980).

\section{Phaeoceros laevis (L.) Prosk.}

Fig. 21-26

Radiossimétrico, heteropolar, circular a subtriangular em vista polar. Trilete, raios com extremidade distal bifurcada. Exospório microequinado a psilado no pólo distal. Espinhos finos, escassos a abundantes, regular a irregularmente distribuídos. Pólo proximal com exospório psilado ou com pouquíssimos espinhos diminutos. Eixo equatorial: 55-63 $\mu \mathrm{m}$. Dados ecológicos: sobre solos úmidos, em locais sombreados. Comum em margem de arroios, rios, campos de cultivo e vertentes, crescendo juntamente com outros briófitos (Menéndez 1962). 

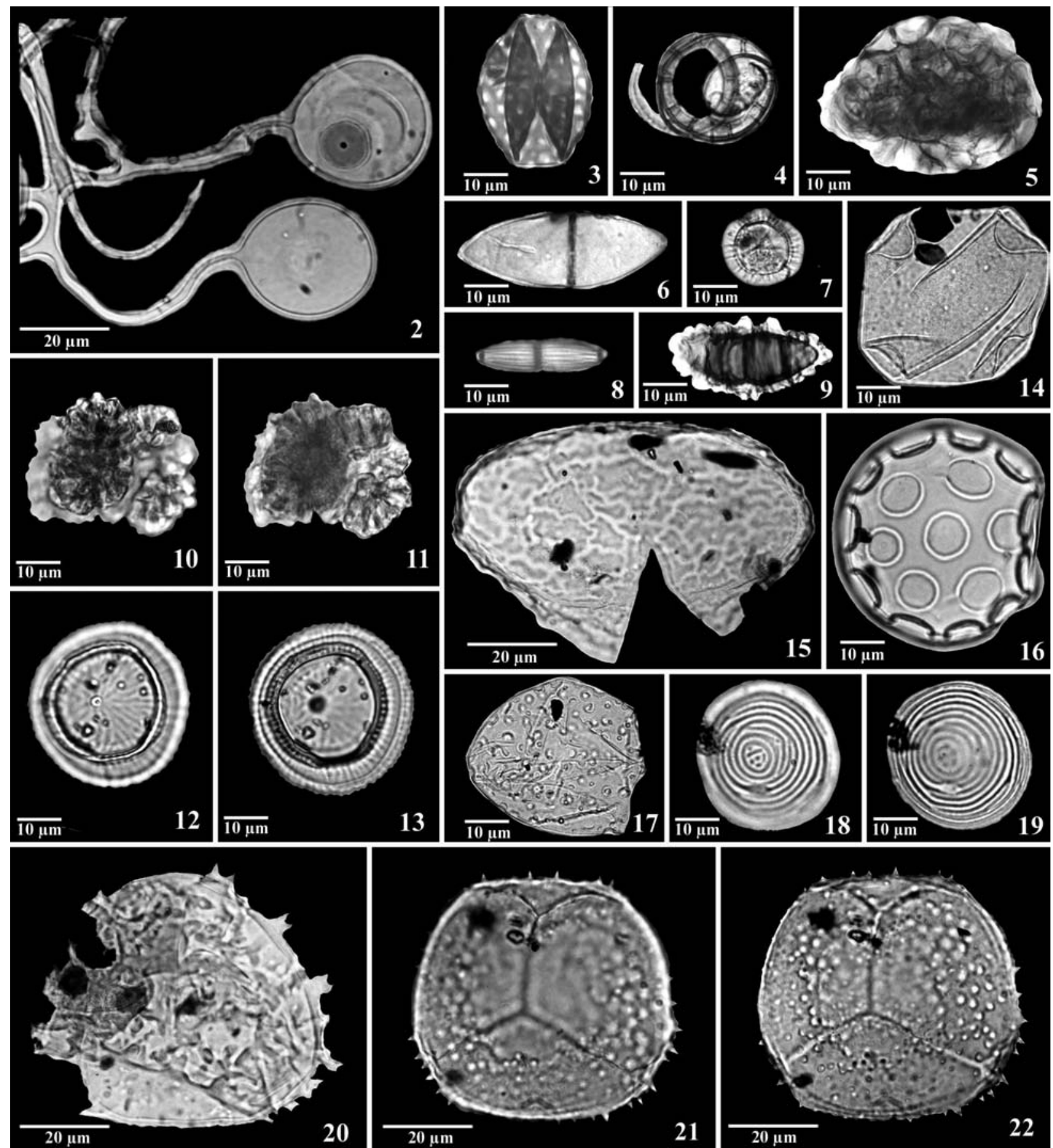

Figuras 2-22. Palinomorfos. 2. Glomus Tul. \& C. Tul. 3. Gelasinospora adjuncta Cain. 4. Tipo Helicoon pluriseptatum Beverw. 5. Tipo Athelia Pers. 6. Esporo 1. 7. Esporo 2. 8. Esporo 3. 9. Esporo 4. 10-11. Botryococcus Kützing: $1^{\circ}-2^{\circ}$ pl. 12-13. Debarya (De Bary) Wittrock, vista frontal: $1^{\circ}-2^{\circ} \mathrm{pl}$. 14. Mougeotia C.A. Agardh. 15. Spirogyra Link, grão fragmentado. 16-17. Zygnema C.A. Agardh. 16. Reentrâncias robustas. 17. Reentrâncias pequenas. 18-19. Pseudoschizaea rubina Rossignol ex Christopher, vista frontal: $1^{\circ}-2^{\circ}$ pl. 20. Aspiromitus punctatus (L.) Schljakov (PD), fragmentado. 21-22. Phaeoceros laevis (L.) Prosk.. (PP): $1^{\circ}-2^{\circ} \mathrm{pl}$. $(\mathrm{pl}=\mathrm{planos}$; $\mathrm{PD}$ = pólo distal; $\mathrm{PP}=$ pólo proximal). 


\section{Phaeoceros Prosk.}

Fig. 27-29

Radiossimétrico, heteropolar, circular em vista polar. Trilete, raios com extremidade distal bifurcada. Exospório psilado. Reentrâncias circulares características entre os raios. Eixo equatorial: 58-69 $\mu \mathrm{m}$. Dados ecológicos: ao que tudo indica, mesmo ambiente de $P$. laevis, já que ambiente úmido parece ser uma característica do gênero (Menéndez 1962).

Divisão Bryophyta

Classe Sphagnopsida

Ordem Sphagnales

Família Sphagnaceae

\section{Sphagnum recurvum P. Beauv}

Fig. 30-31

Radiossimétrico, heteropolar, subtriangular em vista polar, com zonas interangulares levemente convexas. Trilete. Exospório com característico espessamento trilobado no pólo distal, lobos irregularmente dispostos. Pólo proximal com exospório psilado. Eixo equatorial: 60-68 $\mu \mathrm{m}$. Dados ecológicos: distribuição cosmopolita, com preferência a áreas elevadas, frias e temperadas, com pluviosidade anual alta. Constituído por plantas essencialmente higrófilas (subaquáticas), formando pequenos tufos ou extensas colônias, as turfeiras. As espécies de Sphagnum (Dill.) Hedwig habitam também brejos, pântanos, margens de lagos, riachos e rios, vivendo em solos ácidos (Yano et al. 1985; Joly 2002).

\section{Outros esporos}

\section{Briófito}

Fig. 32-34

Radiossimétrico, heteropolar, circular em vista polar. Trilete. Exospório com retículo grosseiro e irregular, por toda a superfície. Eixo equatorial: 75-84 $\mu \mathrm{m}$.

\section{Pteridófitos}

Divisão Pteridophyta

Classe Filicopsida

Subclasse Polypodiidae

Ordem Marattiales

Família Marattiaceae

20. Marattia laevis Sm.

Fig. 35-37
Bilateral, heteropolar, oblato e elipsoidal. Monolete, exospório equinado. Espinhos distribuídos por toda a superfície. Eixo polar: 28-31 $\mu \mathrm{m}$. Eixo equatorial maior: 33-42 $\mu \mathrm{m}$. Dados ecológicos: terrícola, no interior de florestas. Relativamente rara no Rio Grande do Sul (Lorscheitter et al. 1998).

\section{Ordem Polypodiales \\ Subordem Polypodiineae \\ Família Osmundaceae}

\section{Osmunda L.}

Fig. 38-40

Radiossimétrico, heteropolar, circular em vista polar. Robusto. Trilete, raios longos e finos. Exospório fino, facilmente dobrável. Verrucado, verrugas de tamanho, forma e distribuição irregulares. Eixo equatorial: 84-92 $\mu \mathrm{m}$. Observação: freqüentemente encontrado em fragmentos nas amostras. Dados ecológicos: terrícola, em ambientes úmidos, raramente em terrenos com boa drenagem, mais freqüentemente em locais abertos, mas também nos sombreados. $\mathrm{Na}$ América tropical geralmente em ambientes sempre úmidos, abertos ou não, como pântanos, turfeiras, campos e margens de lagos (Tryon \& Tryon 1982; Lorscheitter et al. 1998).

\section{Família Hymenophyllaceae}

\section{Tipo Hymenophyllum Sm.}

Fig. 41

Radiossimétrico, heteropolar, subtriangular a circular em vista polar, hialino. Trilete, exospório papilado. Papilas densamente distribuídas por toda a superfície. Eixo equatorial: 40-46 $\mu \mathrm{m}$. Dados ecológicos: muitas espécies epifíticas ou epipétricas na América tropical. Especialmente em florestas nebulares e florestas úmidas de montanha e, em freqüência mais baixa, em florestas tropicais de altitudes menores. De preferência em locais úmidos e sombreados, como ao longo dos rios e florestas de encosta (Tryon \& Tryon 1982; Lorscheitter et al. 1999).

\section{Família Dicksoniaceae}

\section{Dicksonia sellowiana Hook.}

Fig. 42-43

Radiossimétrico, heteropolar, subtriangular a triangular em vista polar. Robusto. Ângulos truncados com exospório distintamente mais espesso. Trilete, margo desenvolvido. Pólo distal com espessamentos largos e irregulares, o proximal psilado. Eixo equatorial: 

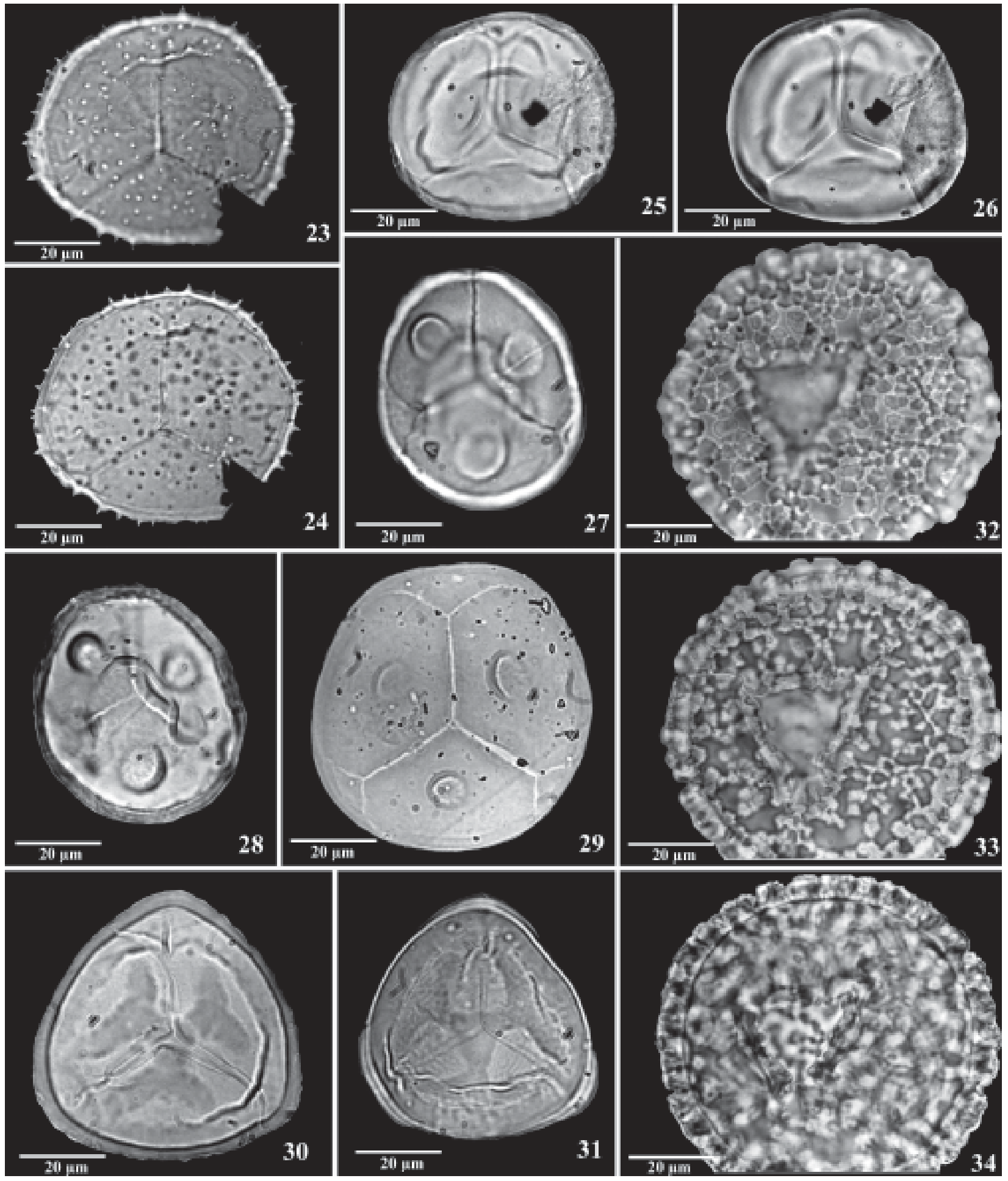

Figuras 23-34. Palinomorfos. 23-26. Phaeoceros laevis (L.) Prosk. 23-24. (PD), equinado (raios vistos por transparência): $1^{\circ}-2^{\circ} \mathrm{pl}$, 25-26. (PP), psilado: $1^{\circ}-2^{\circ} \mathrm{pl}$; 27-29. Phaeoceros Prosk. 27-28. (PP): $1^{\circ}-2^{\circ} \mathrm{pl}, 29$. (PP); 30-31. Sphagnum recurvum P. Beauv. 30. (PP), lobos vistos por transparência, 31. (PD), raios vistos por transparência. $32-34$. Briófito (PP): $1^{\circ}-3^{\circ} \mathrm{pl}$ ( $\mathrm{pl}=$ planos; $\mathrm{PD}=$ pólo distal; $\mathrm{PP}=$ pólo proximal). 
70-76 $\mu \mathrm{m}$. Dados ecológicos: arborescente, com uma grossa camada de raízes adventícias no caudex, mais freqüente em ambientes sombreados. Em matas úmidas de montanha e florestas nebulares na América tropical, ao pé de encostas ou matas de galeria (Tryon \& Tryon 1982; Lorscheitter et al. 1999). Espécie típica da composição florística da mata com Araucária, capaz de sobreviver às condições rigorosas do inverno. No Rio Grande do Sul é encontrada em altitudes de 60 a $1.200 \mathrm{~m}$ (Lorscheitter et al. 1999).

\section{Família Cyatheaceae}

\section{Cyatheaceae}

Fig. 44

Radiossimétrico, heteropolar, subtriangular a triangular em vista polar. Trilete com exospório psilado, uniformemente espessado. Eixo equatorial: 39-69 $\mu \mathrm{m}$. Dados ecológicos: arborescente, com ampla distribuição. Em florestas tropicais de montanha, florestas úmidas de montanha ou em florestas nebulares, como também ao longo dos rios e locais rochosos (Tryon \& Tryon 1982; Lorscheitter et al. 1999).

\section{Família Dennstaedtiaceae}

\section{Hypolepis Bernh.}

Fig. 45-46

Bilateral, heteropolar, oblato e elipsoidal. Monolete. Exospório psilado, perispório equinado. Espinhos pequenos, irregulares, densamente distribuídos, cobrindo toda a superfície. Eixo equatorial maior: 32-41 $\mu \mathrm{m}$. Eixo equatorial menor: 24-32 $\mu \mathrm{m}$. Dados ecológicos: terrícola, no interior ou na borda das florestas, capoeiras, algumas vezes em ambientes úmidos a encharcados e em locais abertos (Tryon \& Tryon 1982). No Rio Grande do Sul é encontrado desde o nível do mar até $1.100 \mathrm{~m}$ de altitude, em florestas (Lorscheitter et al. 2002). Primeira citação para o Quaternário do Rio Grande do Sul.

Família Dryopteridaceae

\section{Tipo Dryopteris Adans.}

Fig. 47

Bilateral, heteropolar, oblato e elipsoidal. Monolete, exospório psilado, perispório com numerosas dobras curtas e irregulares, de superfície psilada. Eixo polar: cerca de $30 \mu \mathrm{m}$. Eixo equatorial maior: cerca de $40 \mu \mathrm{m}$. Dados ecológicos: gênero terrícola, rupestre ou raramente epifítico, ocorrendo em encostas de florestas úmidas, entre rochas, capoeiras, pântanos, campos e penhascos (Tryon \& Tryon 1982).

\section{Família Aspleniaceae}

\section{Asplenium serra Langsd. \& Fisch.} Fig. 48-59

Bilateral, heteropolar, oblato, elipsoidal. Monolete. Exospório psilado, perispório reticulado. Retículo grosseiro e irregular, cobrindo toda a superfície. Altas pilas heterogêneas, formadas pelo perispório interno, sustentam o retículo. Espinhos curtos e isolados podem ocorrer sobre o muro. Eixo polar: cerca de $35 \mu \mathrm{m}$. Eixo equatorial maior: cerca de $40 \mu \mathrm{m}$. Dados ecológicos: terrícola, algumas vezes podendo estar sobre rochas ou como epífita, em florestas e locais sombreados. No Rio Grande do Sul encontra-se desde o nível do mar até cerca de $900 \mathrm{~m}$ de altitude (Lorscheitter et al. 2002). Primeira citação para o Quaternário do Rio Grande do Sul.

\section{Família Blechnaceae}

28. Blechnum cf. imperiale (Fee \& Glaziou) H. Chr. Fig. 50

Bilateral, heteropolar, oblato e elipsoidal. Robusto, freqüentemente plano-convexo em vista equatorial. Coloração amarela escura. Monolete, exospório psilado. Eixo polar: 63-73 $\mu \mathrm{m}$. Eixo equatorial maior: 84-88 $\mu \mathrm{m}$. Dados ecológicos: em geral subarborescente, terrícola, de ampla dispersão em locais pantanosos e úmidos, junto de águas correntes no campo, mas também em locais mais secos, em matas e capoeiras. No Rio Grande do Sul ocorre preferencialmente sobre turfeiras do Planalto leste (Sehnem 1968).

\section{Tipo Blechnum L.}

Fig. 51

Bilateral, heteropolar, oblato e elipsoidal, planoconvexo em vista equatorial. Coloração amarela clara. Monolete, exospório psilado. Eixo polar: 27-35 $\mu \mathrm{m}$. Eixo equatorial maior: 41-53 $\mu \mathrm{m}$. Observação: Tipo Blechnum difere de $B$. cf. imperiale pelo menor tamanho e pela coloração mais clara. Dados ecológicos: gênero composto por plantas terrícolas, rupestres, algumas vezes epifíticas. Na América tropical cresce em florestas tropicais, florestas de montanha e florestas nebulares, ao longo de córregos e rios, também em pântanos e turfeiras, florestas de galeria e savanas. Algumas espécies vivem em locais alterados (Tryon \& Tryon 1982). 

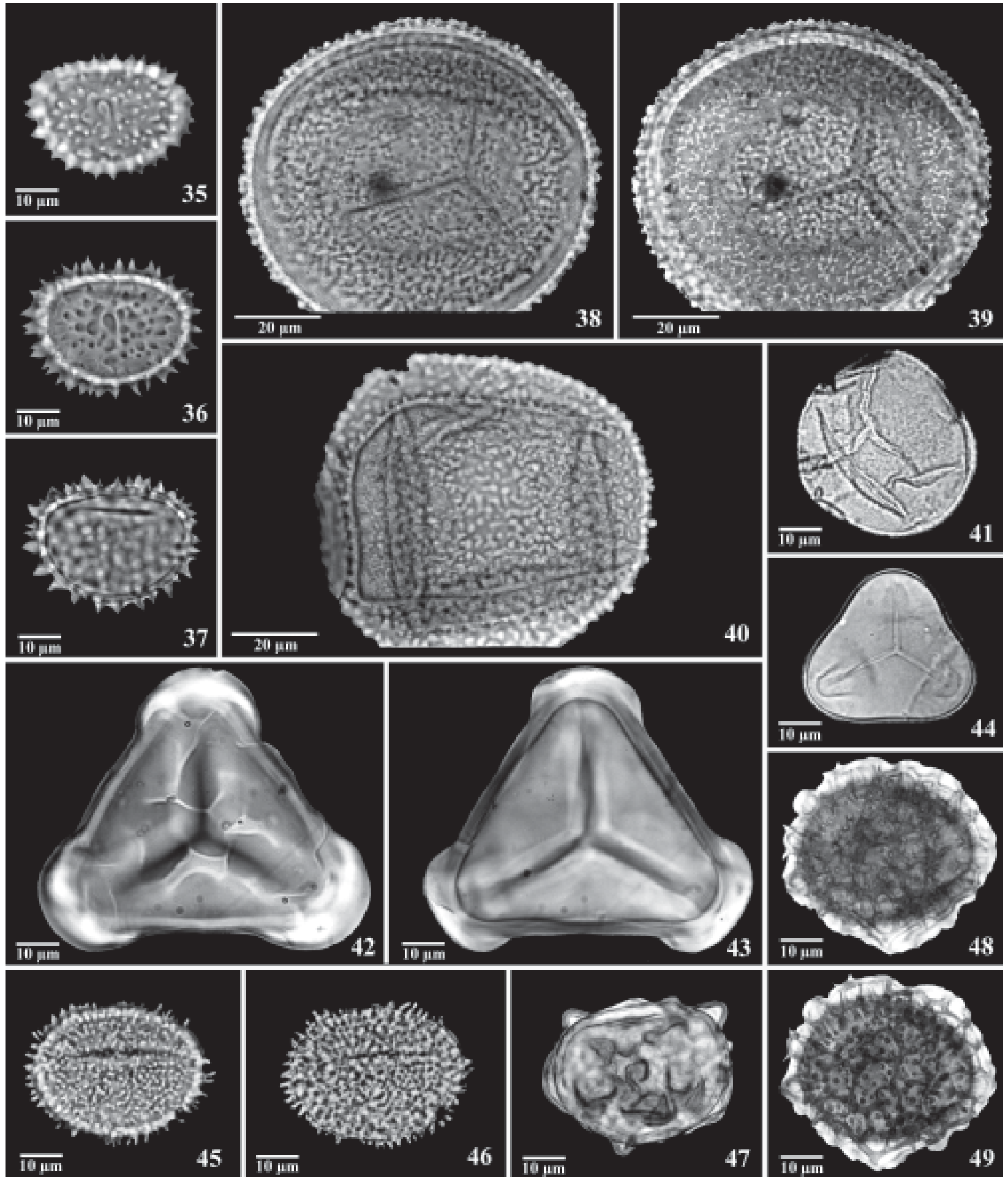

Figuras 35-49. Palinomorfos. 35-37. Marattia laevis Sm. (EQ): $1^{\circ}-3^{\circ} \mathrm{pl}$; 38-40. Osmunda L.. 38-39. (PP): $1^{\circ}-2^{\circ} \mathrm{pl}$, 40. (EQ), com dobras irregulares; 41. Tipo Hymenophyllum Sm. (PP); 42-43. Dicksonia sellowiana Hook. (PD), raios vistos por transparência: $1^{\circ}-2^{\circ} \mathrm{pl}$; 44. Cyatheaceae (PP); 45-46. Hypolepis Bernh. (PD), raio visto por transparência: $1^{\circ}-2^{\circ} \mathrm{pl}$; 47. Tipo Dryopteris Adans. (EQ); 48-49. Asplenium serra Langsd. \& Fisch. $(\mathrm{PD}): 1^{\circ}-2^{\circ} \mathrm{pl} .(\mathrm{pl}=$ planos; $\mathrm{PD}=$ pólo distal; $\mathrm{PP}=$ pólo proximal; $\mathrm{EQ}=$ vista equatorial). 


\section{Família Polypodiaceae}

\section{Pecluma pectinatiformis (Lindm.) M.G. Price}

Fig. 52-54

Bilateral, heteropolar, oblato e elipsoidal. Monolete, com margo. Exospório verrucado. Verrugas robustas, expandidas e distanciadas, de contorno regular. Eixo polar: 38-55 $\mu \mathrm{m}$. Eixo equatorial maior: 49-75 $\mu \mathrm{m}$. Dados ecológicos: epifítica, ocasionalmente epipétrica ou terrícola, em florestas. No Rio Grande do Sul encontra-se entre 30 a $1.100 \mathrm{~m}$ de altitude (Lorscheitter et al. 2005). Primeira citação para o Quaternário do Rio Grande do Sul.

\section{Tipo Microgramma vacciniifolia (Langsd. \&} Fisch.) Copel.

Fig. 55-56

Bilateral, heteropolar, oblato, elipsoidal. Planoconvexo em vista equatorial. Monolete, exospório verrucado. Verrugas robustas, irregulares, distribuídas por toda a superfície, diminuindo de tamanho em direção ao pólo proximal, onde se tornam bem menores. Eixo polar: 50-60 $\mu \mathrm{m}$. Eixo equatorial: 66-82 $\mu \mathrm{m}$. Observação: diferencia-se do Tipo Polypodium por apresentar verrugas bem menores no pólo proximal. Dados ecológicos: espécie epifítica a epipétrica, em locais sombreados e abertos, desde florestas de baixas altitudes até florestas nebulares e em rochas semi-sombreadas. No Rio Grande do Sul é encontrada em quase todas as regiões fisiográficas (Lorscheitter et al. 2005).

\section{Tipo Polypodium hirsutissimum Raddi}

Fig. 57-59

Bilateral, heteropolar, oblato e elipsoidal. Planoconvexo em vista equatorial. Monolete, geralmente com margo desenvolvido. Exospório verrucado. Verrugas pequenas, baixas e delicadas, uniformemente distribuídas. Perispório papilado e com glóbulos grosseiros de distribuição irregular. Eixo polar: cerca de $50 \mu \mathrm{m}$. Eixo equatorial maior: cerca de $70 \mu \mathrm{m}$. Dados ecológicos: a espécie é epifítica, raramente epipétrica ou sobre ramos em decomposição no solo. Em florestas, locais sombreados ou mais abertos. No Rio Grande do Sul encontra-se desde o nível do mar até $1.200 \mathrm{~m}$ de altitude (Lorscheitter et al. 2005). Primeira citação para o Quaternário do Rio Grande do Sul.

\section{Tipo Polypodium L.}

Fig. 60

Bilateral, heteropolar, oblato a suboblato, elipsoidal. Plano-convexo em vista equatorial. Monolete, exospório verrucado. Verrugas pequenas, uniformemente distribuídas por toda a superfície. Eixo polar: 49-71 $\mu \mathrm{m}$. Eixo equatorial maior: 70-92 $\mu \mathrm{m}$. Dados ecológicos: gênero terrícola, rupestre ou epifítico. $\mathrm{Na}$ América tropical as espécies do gênero geralmente crescem nas florestas tropicais, de montanha, nebulares e de galeria, ou em savanas com vegetação alta (Tryon \& Tryon 1982). No Rio Grande do Sul o gênero ocorre, em geral, como epifítico, em florestas (Lorscheitter et al. 2005).

Classe Lycopodiopsida

Ordem Lycopodiales

Família Lycopodiaceae

\section{Huperzia Bernh.}

Fig. 61-63

Radiossimétrico, heteropolar, piramidal, subtriangular em vista polar. Trilete. Exospório foveolado no pólo distal, psilado no proximal. Perfurações regularmente distribuídas. Eixo equatorial: 42-47 $\mu \mathrm{m}$. Dados ecológicos: gênero epifítico ou rupestre, no interior ou na borda das matas e em locais úmidos (Lorscheitter et al. 1998).

\section{Lycopodiella alopecuroides (L.) Cranfill} Fig. 64-67

Radiossimétrico, heteropolar, subtriangular a circular em vista polar, levemente cingulado. Trilete, com margo. Exospório rugulado-reticulado no pólo distal, com projeções grosseiras e pequeno espessamento aproximadamente quadrangular central. Pólo proximal com exospório tuberculado entre os raios. Tubérculos pequenos. Eixo equatorial: 56-59 $\mu$ m. Dados ecológicos: terrícola, geralmente em turfeiras e campos úmidos. Em todas as regiões fisiográficas do Rio Grande do Sul (Lorscheitter et al. 1998).

\section{Tipo Lycopodium clavatum L.}

Fig. 68-69

Radiossimétrico, heteropolar, subtriangular em vista polar. Trilete. Exospório reticulado. Retículo grosseiro no pólo distal. Pólo proximal com retículo irregularmente aberto, desaparecendo na porção mais central, onde o exospório se torna psilado. Eixo equatorial: cerca de $40 \mu \mathrm{m}$. Dados ecológicos: terrícola, geralmente em capoeiras e ambientes semiabertos (Tryon \& Tryon 1982). Em todas as regiões fisiográficas do Rio Grande do Sul (Lorscheitter et al. 1998) 


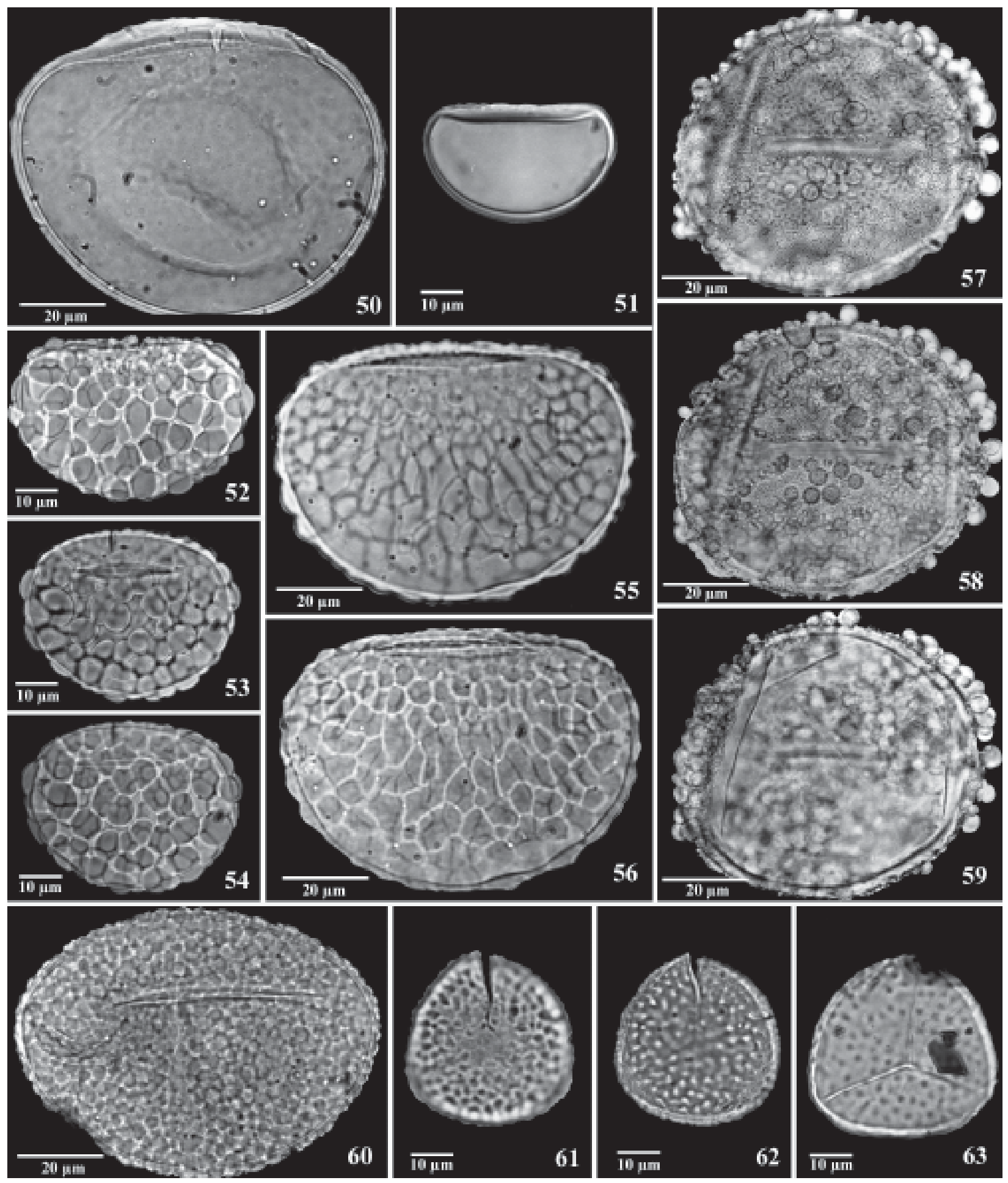

Figuras 50-63. Palinomorfos. 50. Blechnum cf. imperiale (Fee \& Glaziou) H. Chr. (EQ); 51. Tipo Blechnum L. (EQ); 52-54. Pecluma pectinatiformis (Lindm.) M.G. Price. 52. (EQ), 53-54. (oblíquo): $1^{\circ}-2^{\circ} \mathrm{pl}$; 55-56. Tipo Microgramma vacciniifolia (Langsd. \& Fisch.) Copel. (EQ): $1^{\circ}-2^{\circ} \mathrm{pl} ; 57-59$. Tipo Polypodium hirsutissimum Raddi (PP): $1^{\circ}-3^{\circ} \mathrm{pl} ; 60$. Tipo Polypodium L. (PP); 61-63. Huperzia Bernh.. 61-62. (PD): $1^{\circ}-2^{\circ} \mathrm{pl}, 63$. $(\mathrm{PP}) .(\mathrm{pl}=$ planos; $\mathrm{PD}=$ pólo distal; $\mathrm{PP}=$ pólo proximal; $\mathrm{EQ}=$ vista equatorial). 
142 Scherer \& Lorscheitter: Palinomorfos de fungos e criptógamas em sedimentos quaternários de duas matas...
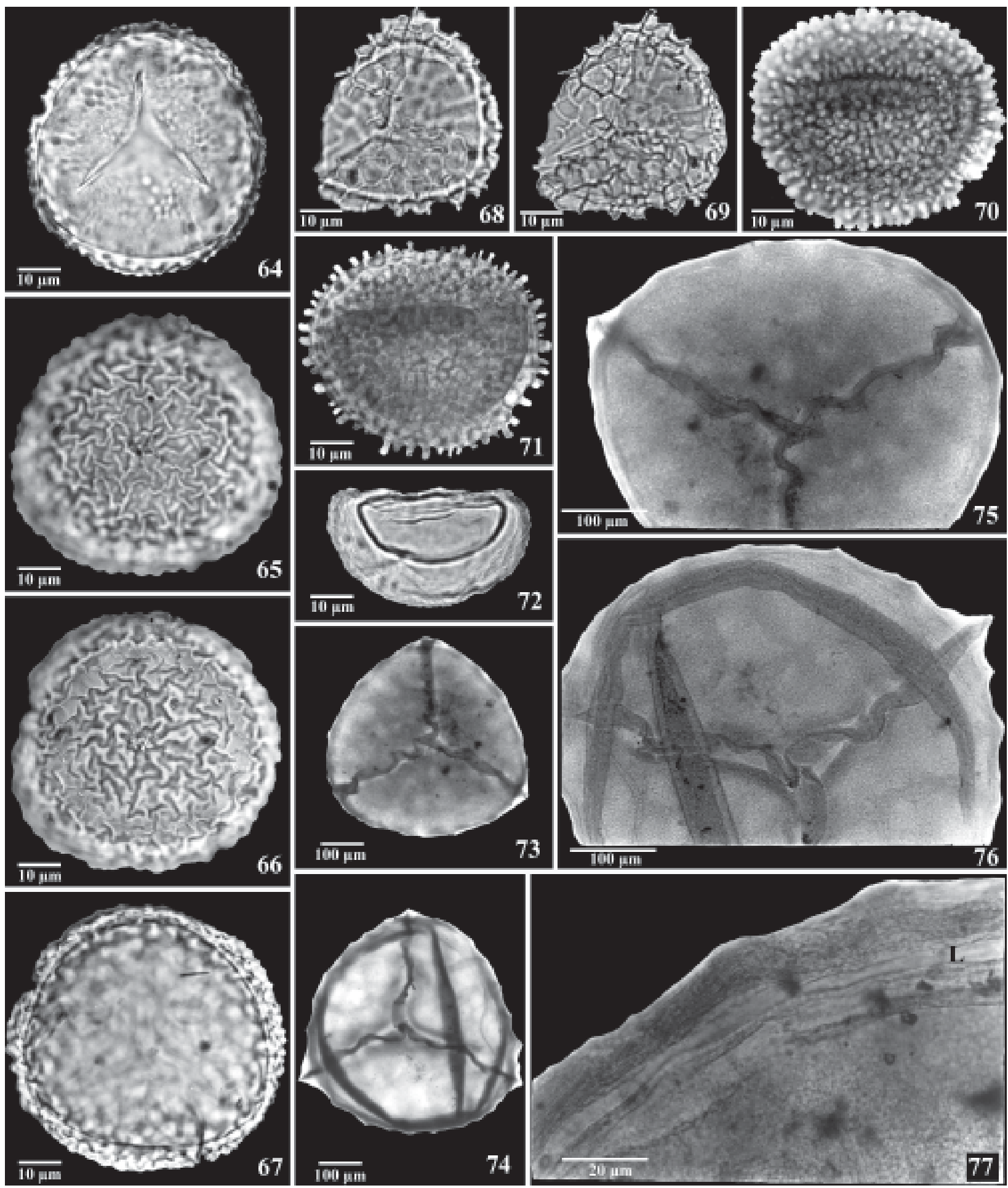

Figuras 64-77. Palinomorfos. 64-67. Lycopodiella alopecuroides (L.) Cranfill. 64. (PP), 65-67. (PD): $1^{\circ}-3^{\circ}$ pl. 68-69. Tipo Lycopodium clavatum L. (PD), fragmentado: $1^{\circ}-2^{\circ}$ pl. 70-71. Selaginella marginata (Humb. \& Bonpl. ex Willd.) Spring (oblíquo): $1^{\circ}-2^{\circ} \mathrm{pl} ; 72-77$. Isoetes L. 72. Micrósporo (EQ), paraexospório desenvolvido. 73-77. Megásporos. 73. (PD), escabrado, raios vistos por transparência. 74. (PP), leve retículo visto por transparência, raios com aurículas evidentes. 75. (PD), escabrado, raios vistos por transparência. 76. (PP), escabrado, raios com aurículas evidentes. 77. Detalhe do exospório lamelar com lacuna (L). (pl = planos; PD = pólo distal; $\mathrm{PP}=$ pólo proximal $; \mathrm{EQ}=$ vista equatorial $)$ 
Ordem Selaginellales

Família Selaginellaceae

37. Selaginella marginata (Humb. \& Bonpl. ex Willd.) Spring

Fig. 70-71

Radiossimétrico, heteropolar, subtriangular a circular em vista polar. Trilete, exospório baculado. Báculas pequenas, ainda menores no pólo proximal, densamente distribuídas. Eixo equatorial: 42-56 $\mu \mathrm{m}$. Dados ecológicos: terrícola, em ambientes úmidos. Em todas as regiões fisiográficas do Rio Grande do Sul (Lorscheitter et al. 1998).

Ordem Isoetales

Família Isoetaceae

38. Isoetes $\mathrm{L}$.

Micrósporo

Fig. 72

Bilateral, heteropolar, oblato. Elipsoidal, hialino. Plano-convexo em vista equatorial. Monolete, exospório psilado. Paraexospório psilado a escabrado, envolvendo frouxamente o grão, podendo estar a uma distância considerável deste, especialmente no pólo distal. Eixo polar: com paraexospório: $28-32 \mu \mathrm{m}$, sem paraexospório: 17-24 $\mu \mathrm{m}$. Eixo equatorial maior: com paraexospório: 42-47 $\mu \mathrm{m}$, sem paraexospório: 30-36 $\mu \mathrm{m}$. Eixo equatorial menor: com paraexospório: cerca de $30 \mu \mathrm{m}$, sem paraexospório: cerca de $20 \mu \mathrm{m}$.

Megásporo

Fig. 73-77

Radiossimétrico, heteropolar. Subtriangular a circular em vista polar, com cingulum. Trilete, em geral com extremidades distintamente auriculadas. Exospório levemente reticulado a escabrado no pólo distal, psilado a escabrado no proximal. Exospório externo lamelar e lacunoso, lacuna de espessura variável. Eixo equatorial: 465-556 $\mu \mathrm{m}$. Observação: os megásporos foram encontrados no material retido na malha de $250 \mu \mathrm{m}$, durante a filtragem das amostras. Dados ecológicos: aquático, palustre ou terrícola, geralmente submerso e/ou anfíbio em lagos, preferencialmente nas águas rasas, poças ou córregos. Também na margem de lagos, solos arenosos úmidos e em turfeiras (Tryon \& Tryon 1982). Distribuição cosmopolita (Tryon \& Tryon 1982; Fuchs-Eckert 1986), ocorrendo em banhados e águas correntes no Rio Grande do Sul e Santa Catarina (Fuchs-Eckert 1986).
Do total de 38 palinomorfos examinados nos dois perfis sedimentares, cinco são citações novas para o Quaternário do Rio Grande do Sul: Tipo Helicoon pluriseptatum Beverw., Hypolepis Bernh., Asplenium serra Langsd. \& Fisch., Pecluma pectinatiformis (Lindm.) M.G. Price e Tipo Polypodium hirsutissimum Raddi.

A grande quantidade de distintos palinomorfos de fungos e de criptógamas, encontrada nas amostras, reflete diversos ambientes, mostrando a potencialidade desse material, junto com pólen, em oferecer relevantes informações na pesquisa sobre a gênese e a dinâmica da mata com Araucária nos últimos milênios, influenciados pelas mudanças climáticas no Planalto sul-brasileiro.

\section{Agradecimentos}

As autoras agradecem ao CNPq, pelo auxílio financeiro e pelas bolsas concedidas, que tornaram possível a realização deste trabalho.

\section{Referências bibliográficas}

Alexopoulos, C.J.; Mims, C.W. \& Blackwell, M. 1996. Introductory Mycology. $4^{\text {th }}$ ed. New York, John Wiley \& Sons Inc.

Backes, A. 1988. Condicionamento climático e distribuição geográfica de Araucaria angustifolia (Bertol.) Kuntze no Brasil. Pesquisas, Botânica 39: 5-39.

Behling, H.; Bauermann, S.G. \& Neves, P.C.P. 2001. Holocene environmental changes in São Francisco de Paula region, southern Brazil. Journal of South American Earth Sciences 14: 631-639.

Behling, H.; Pillar, V.D.P.; Orlóci, L. \& Bauermann, S.G. 2004. Late Quaternary Araucaria forest, grassland (campos), fire and climate dynamics, studied by high resolution pollen, charcoal and multivariate analysis of the Cambará do Sul core in southern Brazil. Palaeogeography, Palaeoclimatology, Palaeoecology 203: 277-297.

Berglund, B.E. 1986. Handbook of Holocene Palaeoecology and Palaeohydrology. New York, John Wiley \& Sons.

Bold, H.C.; Alexopoulos, C.J. \& Delevoryas, T. 1987. Morphology of Plants and Fungi. $5^{\text {th }}$ ed. New York, Harper \& Row Publishers.

Christopher, R.A. 1976. Morphology and taxonomic status of Pseudoschizaea Thiergart and Frantz ex R. Potonie Emend. Micropaleontology 22: 143-150.

Erdtman, G. 1969. Handbook of Palynology. New York, Hafner Publishing Co.

Faegri, K. \& Iversen, J. 1989. Textbook of pollen analysis. $4^{\text {th }}$ ed. New York, John Wiley \& Sons.

Fuchs-Eckert, H.P. 1986. Isoetáceas. Pp. 1-42. In: R. Reitz (ed.). Flora Ilustrada Catarinense. Itajaí, Herbário Barbosa Rodrigues. 
Hooghiemstra, H. 1984. Vegetational and climatic history of the High Plain of Bogotá, Colombia: A continuous record of the last 3.5 million years. Amsterdam, Strauss \& Cramer.

Hueck, K. 1953. Distribuição e habitat natural do Pinheiro do Paraná (Araucaria angustifolia). Boletim da Faculdade de Filosofia e Ciências 10: 1-24.

Ingold, C.T. \& Hudson, H.J. 1993. The biology of fungi. $6^{\text {th }}$ ed. London, Chapman \& Hall.

Joly, A.B. 2002. Botânica: introdução à taxonomia vegetal. $13^{a}$ ed. São Paulo, Editora Nacional.

Kirk, P.M.; Cannon, P.F.; David, J.C. \& Stalpers, J.A. 2001. Dictionary of the fungi. $9^{\text {th }}$ ed. Cambridge, CAB Internacional.

Leonhardt, A. \& Lorscheitter, M.L. 2007. Palinomorfos do perfil sedimentar de uma turfeira em são Francisco de Paula, Planalto Leste do Rio Grande do Sul, sul do Brasil. Revista Brasileira de Botânica 30: 47-59.

Lorscheitter, M.L. 1988. Palinologia de sedimentos quaternários do testemunho T15, Cone do Rio Grande, Atlântico Sul, Brasil. Descrições taxonômicas. Pesquisas 21: 61-117.

Lorscheitter, M.L.; Ashraf, A.R.; Bueno, R.M. \& Mosbrugger, V. 1998. Pteridophyte of Rio Grande do Sul flora, Brazil. Part I. Palaeontographica 246: 1-113.

Lorscheitter, M.L.; Ashraf, A.R.; Windisch, P.G. \& Mosbrugger, V. 1999. Pteridophyte of Rio Grande do Sul flora, Brazil. Part II. Palaeontographica 251: 71-235.

Lorscheitter, M.L.; Ashraf, A.R.; Windisch, P.G. \& Mosbrugger, V. 2002. Pteridophyte of Rio Grande do Sul flora, Brazil. Part IV. Palaeontographica 263: 1-159.

Lorscheitter, M.L.; Ashraf, A.R.; Windisch, P.G. \& Mosbrugger, V. 2005. Pteridophyte of Rio Grande do Sul flora, Brazil. Part V. Palaeontographica 270: 1-180.

Menéndez, G.G.H. 1962. Estudio de las Anthocerotales y Marchantiales de la Argentina. Tucumán, Universidad Nacional de Tucumán, Instituto Miguel Lillo.

Moreira-Souza, M.; Trufem, S.F.B.; Gomes-Da-Costa, S.M. \& Cardoso, E.J.B.N. 2003. Arbuscular mycorrhizal fungi associated with Araucaria angustifolia (Bert.) O. Ktze. Mycorrhiza 13: 211-215.

Neves, P.C.P. \& Bauermann. S.G. 2003. Catálogo palinológico de coberturas quaternárias do Estado do Rio Grande do Sul (Guaíba e Capão do Leão), Brasil. Descrições taxonômicas - Parte I: fungos, algas, palinomorfos outros e fragmentos de invertebrados. Pesquisas, Botânica 53: 121-149.
Neves, P.C.P. \& Lorscheitter, M.L. 1992. Palinologia de sedimentos de uma mata tropical paludosa em Terra de Areia, Planície Costeira Norte, Rio Grande do Sul, Brasil. Descrições Taxonômicas, Parte I: fungos, algas, briófitos, pteridófitos, palinomorfos outros e fragmentos de invertebrados. Acta Geológica Leopoldensia XV(36): 83-114.

Punt, W.; Blackmore, S.; Nilsson, S. \& Thomas, A.LE. 2007. Glossary of pollen and spore terminology. Second edition revised by Peter Hoen, Review of Palaeobotany and Palynology 143: 1-81.

Rossignol, M. 1962. Analyse pollinique de sédiments marins quaternaries em Israel. II Sédiments Pleistocenes. Pollen et Spores 4: 121-148.

Roth, L. \& Lorscheitter, M.L. 1993. Palynology of a bog in Parque Nacional de Aparados da Serra, East Plateau of Rio Grande do Sul, Brazil. Quaternary of South America and Antarctic Peninsula 8: 39-69.

Round, F.E. 1973. The Biology of the Algae. $2^{\text {nd }}$ ed. London, Edward Arnold Limited.

Schultz, A.R.H. 1980. Introdução à botânica sistemática. $5^{\text {a }}$ ed., v.1. Porto Alegre, Editora da Universidade Federal do Rio Grande do Sul.

Schüßler, A.; Schwarzott, D. \& Walker, C. 2001. A new fungal phylum, the Glomeromycota: phylogeny and evolution. Mycological Research 105: 1413-1421.

Sehnem, A. 1968. Blecnáceas. Pp. 1-90. In: R. Reitz (ed.). Flora Ilustrada Catarinense. Itajaí, Herbário Barbosa Rodrigues.

Smith, G.M. 1987. Botanica criptogamica. $4^{\text {a }}$ ed., v.1. Lisboa, Fundação Calouste Gulbenkian.

Tryon, R.M. \& Tryon, A.F. 1982. Ferns and allied plants. New York, Springer-Verlag.

Van Geel, B. 1978. A paleoecological study of Holocene peat bog section in Germany and the Netherlands. Review of Palaeobotany and Palynology 25: 1-120.

Van Geel, B. \& van der Hammen, T. 1977. Zygnemataceae in Quaternary Colombian sediments. Review of Palaeobotany and Palynology 25: 377-392.

Yano, O.; Pirani, J.R. \& Santos, D.P. 1985. O gênero Sphagnum (Bryopsida) nas regiões Sul e Sudeste do Brasil. Revista Brasileira de Botânica 8: 55-80. 